\title{
Development of Fast Dissolving Tablets of Nisoldipine by Solid Dispersion Technology using Poloxamer 407 and Poloxamer 188
}

\author{
Manimaran Vasanthan and Damodharan Narayanasamy* \\ Department of Pharmaceutics, SRM College of Pharmacy, SRM University, Kattankulathur, Tamilnadu, INDIA.
}

\begin{abstract}
Objective: The aim of the present study is to design oral fast-release tablets of nisoldipine and to optimize the drug dissolution profile by modifying the carrier concentration. Poloxamer 407 and Poloxamer 188 were selected as carriers for preparing the solid dispersion (SD) by solvent evaporation method with different drug polymer ratios. Methods: The prepared solid dispersions were analyzed for physical state, drug:carrier interactions by $X$ ray diffraction, infrared spectroscopy, differential scanning calorimetry and scanning electron microscopy. Results: The dissolution studies revealed that all solid dispersions showed increased dissolution rate whencompared to pure nisoldipine. Among the two polymers used, poloxamer 407(P 407) was found to be better than poloxamer 188(P 188) in the enhancement of dissolution efficiency. The tablets were formulated using solid dispersion of nisoldipine containing poloxamer 407 as carrier. Conclusion: The results exhibited that poloxamer 407 SD based tablets gave a significantly higher release of nisoldipine when compared with control tablets. Infrared spectral studies showed that there was no interaction between thenisoldipine
\end{abstract}

and its formulation with different carriers used in the preparation of solid dispersions. X-ray diffraction studies revealed that the degree of crystallinity of nisoldipine decreased when the concentration of carriers increased, which showed that the drug is in amorphous nature.

Key words: Fast dissolving tablets, Poloxamer 407, Poloxamer 188, Solid dispersion, Superdisintergrants.

Correspondence :

Prof. N. Damodharan,

Professor and Head, Department of Pharmaceutics, SRM College of Pharmacy, SRM University, Kattankulathur, Kancheepuram, INDIA.

Phone no: 9790725487

E-mail: damodharan.n@ktr.srmuniv.ac.in

DOI: 10.5530/jyp.2016.4.9

\section{INTRODUCTION}

Drugs which belong to class II of biopharmaceutical classification system are characterized by high membrane permeability, slow dissolution rate and high per oral dose. The solubility or dissolution rate of a drug in this category is therefore a key factor in determining the rate and extent of its absorption. ${ }^{1}$ Solid dispersion technology can be used to enhance the dissolution rate of BCS class II drugs thereby improving their bioavailability. Enhancement of dissolution rate is important to attain the suitable blood concentration for increased therapeutic effect, as their dissolution rates are typically the rate limiting step for bioavailability. Several methods have been reported for enhancement of solubility and dissolution rate of poorly aqueous soluble drugs, namely increasing the surface area by reducing the particle size, using surfactant systems, preparation of water soluble complexes, pro drug approach, salt formation of the drug, decreasing the crystallinity of the drug through the formation of solid solutions. The most common method is reducing the particle size by micronization technique. The technique is disadvantaged by the greater tendency of size reduced particles to stick together which leads to formation of larger agglomerates which in turn leads to reduction in effective surface area for dissolution. Now a days the most effective method to improving the dissolution rate is the use of solid dispersion technique but this is reliant on optimization of carrier and solvent. ${ }^{2}$ The solid dispersions are two component systems consisting of a hydrophilic carrier in which the drug is incorporated. The solid dispersion technology provides the possibility to reduce the drug particle size almost to a molecular level and increased wettability. ${ }^{3}$ In addition to this, a transformation of the drug from the crystalline form to amorphous form can occur, which can be beneficial since dissolution of an amorphous drug does not require energy to break up the crystalline lattice.

Another interesting method to improve the dissolution of solid dispersion tablet is with the incorporation of superdisintegrants, because superdisintegrants do not irritate the gastrointestinal tract and can be used at low amounts in the formulations. ${ }^{4}$ Crospovidone, croscarmellose sodium and sodium starch glycolate were used as superdisintegrants.

Nisoldipine is an anti hypertensive agent which may be used alone or in combination with other agents in the management of hypertension and it belong to BCS class II category, therefore solid dispersion technique can be used to enhance the dissolution rate of drug. ${ }^{4}$ Nisoldipine is a 1,4-dihydropyridine calcium channel blocker. It acts primarily on vascular smooth muscle cells by stabilizing voltage gated L-type calcium channels in their inactive conformation. By inhibiting the influx of calcium in smooth muscle cells, nisoldipine prevents calcium dependent smooth muscle contraction and subsequent vasoconstriction. Poloxamer 407 (P 407) and poloxamer 188(P 188) were used as the carriers for the preparation of solid dispersions with nisoldipine. Poloxamer is a synthetic block copolymer of ethylene oxide and propylene oxide widely used in pharmaceutical preparations. ${ }^{5}$

\section{MATERIALS AND METHODS}

\section{Materials}

Nisoldipine, poloxamer 407 and poloxamer 188 were obtained from orchid chemicals \&Pharmaceutics Ltd, Chennai. All other chemicals were of reagent grade and used without purification.

\section{Preparation of solid dispersions and physical mixtures}

The physical mixtures of nisoldipine were prepared by mixing the drug with P 407 and P 188 separately in a mortar for 2-3 min until a homogenous mixture was obtained. The resulting mixture was stored in a vacuum desiccator for one week.

In solvent evaporation method dichloromethane and ethanol was used as solvent and five different ratios of drug and polymer were used (1:1, $1: 2,1: 3,1: 4,1: 5)$ to prepare solid dispersions of nisoldipine. ${ }^{6}$ Respective amount of carrier was dissolved in required amount of dichloromethane and ethanol taken in a conical flask to get a clear completely soluble polymeric solution by using magnetic stirrer. The weighed amount of 
nisoldipine was added to this solution carefully with constant stirring.? Stirring was continued until the drug is completely dissolved in the polymeric solution. Then the solvent was removed by evaporation at $40^{\circ} \mathrm{C}$ under vacuum. The mass obtained was further dried in a desiccator. The dried mass was then pulverized and sifted through mesh no $60 .^{8}$

\section{Drug content uniformity of SDs}

The nisoldipine solid dispersions prepared were tested for drug content uniformity. From each batch, the SDs equivalent to $20 \mathrm{mg}$ of nisoldipine were taken and analyzed for drug content uniformity. ${ }^{9}$ An accurately weighed quantity of nisoldipine SDs were taken in a $100 \mathrm{ml}$ volumetric flask and dissolved in ethanol. The stock solutions were filtered, suitably diluted and assayed for drug content using a Schimadzu UV visible spectrophotometer. ${ }^{10}$

\section{Infra red Spectral analysis}

Compatibility studies of nisoldipine and the carriers were carried out by using fourier transform infrared (FTIR) spectroscopy. Fourier transform infrared spectra of the samples were obtained in the range of 4000 to 450 $\mathrm{cm}^{-1}$ using a perkinelmer-FT-IR $8201 \mathrm{PC}$ spectrophotometer by the $\mathrm{KBr}$ disc method. ${ }^{11}$

\section{Powdered $X$ ray diffraction studies}

The powdered X-ray diffraction patterns were recorded using x'pert proanalytical diffractometer with $\mathrm{Cu}$ as anode material and operated at a voltage of $30 \mathrm{kv}$ and a current of $15 \mathrm{~mA}$. The samples were analyzed in the $2 \theta$ angle range of $0^{\circ}-1000^{\circ}$ and the process parameters were set as follows-sampling width of $0.010^{\circ}(2 \theta)$ at a scanning speed of $1^{\circ} / \mathrm{min}$ and scan mode set is continuous. ${ }^{12}$

\section{Differential scanning calorimetry}

The DSC studies of pure drug, carriers and solid dispersions were carried out using DSC-60 (Schimadzu corporation Japan) instrument with an intra cooler. All standard was used to calibrate the DSC temperature the samples were hermetically sealed in aluminum pans and heated at a constant rate at $5^{\circ} \mathrm{C} / \mathrm{min}$ over a temperature range of $25-175^{\circ} \mathrm{C}$. An inert atmosphere was maintained by purging nitrogen gas at flow rate of $50 \mathrm{ml} / \mathrm{mins}^{13}$

\section{Scanning electron microscopy}

The surface morphology of nisoldipine, P 407, P 188 and SDs were examined using scanning electron microscope. The samples were mounted on a double faced adhesive tape and sputtered with thin gold palladium layer using sputter coater unit and the surface topography was analyzed with a scanning electron microscopy. ${ }^{14}$ (Steroscan 440, Leo Leica, Cambridge , U.K)

\section{Dissolution studies}

Dissolution studiesof nisoldipine pure drug, and SDs were performed according to method described in USP XXIV using apparatus 2 with the paddle rotating at $50 \mathrm{rpm}$ in $900 \mathrm{ml}$ of phosphate buffer $\mathrm{pH} 6.8$ at $37^{\circ} \mathrm{C} .{ }^{15}$ Solid Dispersion powders equivalent to $20 \mathrm{mg}$ of nisoldipine were taken for dissolution. Aliquots of $5 \mathrm{ml}$ were withdrawn at selected time intervals $(10,20,30,40,60$ and $90 \mathrm{~min})$ and the sample is replaced with the fresh medium which is pre warmed to $37^{\circ} \mathrm{C}$ each time. The absorbance was determined by UV spectroscopy at $237 \mathrm{~nm} .{ }^{16}$

\section{Preparation of fast dissolving tablets}

The SD formulation which showed highest dissolution rate was formulated in to tablets using various proportions of sodium starch glycolate, croscarmellose sodium and crospovidone as superdisintegrants. ${ }^{17}$ The SDs equivalent to $20 \mathrm{mg}$ of nisoldipine were taken and the composition of the prepared tablet formulation is presented in Table 1. The drug or its equivalent SDs were mixed with the excipients for $15 \mathrm{~min}$ by bottle method, before compression into tablets. ${ }^{18}$ The tabletting process employed cadmach 16 station rotary punch tablet machine and the compression force was adjusted to prepare the tablets having a hardness of 4-5 kP. ${ }^{19}$

\section{Evaluation of fast dissolving tablets}

\section{Uniformity of weight}

The USP weight variation test was conducted by weighing 20 tablets individually, calculating the average weight and comparing the individual tablet weights to the average. For tablets weighing $200 \mathrm{mg}$ the allowed percentage deviation is $7.5 \%$. The prepared tablets meet the USP test if not more than two tablets are outside the limit and no tablet differs by more than twice the limit. ${ }^{20}$

\section{Tablet friability}

The friability of the tablets were measured in rochiefriablator. 20 tablets were weighed and placed in friabilator and subjected to 100 revolutions at $25 \mathrm{rpm}$ for $4 \mathrm{~min}$. The tablets were wiped with clean cloth and weighed again. The friability was calculated as the percentage loss which should not exceed $1 \% .^{21}$

\section{Drug content}

30 tablets were randomly selected and from these 10 tablets were individually subjected to drug content determination. ${ }^{22}$ The tablets were considered acceptable if the content of each of at least 9 tablets were in the range of $85-115 \%$ of the labeled amount of the drug. The tenth tablet should not contain $<75 \%$ or $>125 \%$ of the labeled content. If these conditions were not met remaining 20 tablets must be analyzed individually and all they should be within the limit. ${ }^{23}$

\section{RESULTS}

\section{Drug content}

The nisoldipine SDs were tested for drug content by UV method, the percentage drug content was found to be $97.5 \pm 3 \% \mathrm{w} / \mathrm{w}$ and the results were shown in Table 2 .

\section{Infra red spectral analysis}

The IR spectra of nisoldipine, P 407, P 188 and solid dispersions were shown in Figure 1, 2. The spectrum of pure drug shows strong absorption band at $3323 \mathrm{~cm}^{-1}$ due to the stretching of the N-H group of dihydropyridine (DPH) moiety. The bands between 2885 and $3243 \mathrm{~cm}^{-1}$ can be due to the stretching of aromatic and aliphatic $\mathrm{C}-\mathrm{H}$ bond. The two strong absorption bands at 1654 and $1705 \mathrm{~cm}^{-1} \mathrm{can}$ be attributed to the carbonyl group of the two side chain in the structure of $\mathrm{DPH}$. The $\mathrm{NO}_{2}$ stretching produced two absorption bands one at 1534 and other at $1348 \mathrm{~cm}^{-1}$. The band at $1492 \mathrm{~cm}^{-1}$ is for aromatic $\mathrm{C}=\mathrm{C}$ bond. The two bands at 1215 and $1113 \mathrm{~cm}^{-1}$ are due to C-O stretching. The spectrum of pure P 407 and P 188 shown in Figure 1, 2 were in good agreement with published data on polymer.

\section{Powdered $X$ ray diffraction studies}

In order to clarify the physicochemical characteristics of all SDs, X-ray diffraction measurements were conducted. The XRD pattern of pure nisoldipine exhibited sharp, highly intense and less diffused peaks indicating the crystalline nature of pure drug. It showed sharp diffraction peaks at 2q degree equal to $9.450,11.490,12.580,19.160,22.880,26.320$ and 27.540. The XRD of solid dispersions showed reduction in diffraction peak intensity at $2 \mathrm{q}$ values at $9.490,11.460,12.600,23.490,26.380$, and 27.220 indicates that the significant reduction in crystallinity of nisoldipine (Figure 3, 4). 
Table 1: Master formula for preparation of nisoldipine tablets

\begin{tabular}{cccccccccc}
\hline Ingredients & F1 & F2 & F3 & F4 & F5 & F6 & F7 & F8 & F9 \\
\hline $\begin{array}{c}\text { Nisoldipine P 407 1:5 } \\
\quad 120\end{array}$ & 120 & 120 & 120 & 120 & 120 & 120 & 120 & 120 \\
$\begin{array}{c}\text { Solid dispersion } \\
\text { Crospovidone }\end{array}$ & 4 & 6 & 8 & - & - & - & - & - & - \\
Croscarmellose sodium & - & - & - & 8 & 10 & 12 & - & - & - \\
Sodium starch glycolate & - & - & - & - & - & - & 8 & 10 & 12 \\
Magnesium stearate & 2 & 2 & 2 & 2 & 2 & 2 & 2 & 2 & 2 \\
$\quad$ Aerosil & 2 & 2 & 2 & 2 & 2 & 2 & 2 & 2 & 2 \\
Microcrystalline cellulose & 72 & 70 & 68 & 68 & 66 & 64 & 68 & 66 & 64 \\
\hline
\end{tabular}

Table 2: Drug content uniformity of solid dispersions of nisoldipine

\begin{tabular}{cc}
\hline Solid dispersions (Drug:carrier) & \% Drug content \\
\hline P 407 1:1 & $96.8 \pm 0.35$ \\
P 407 1:2 & $98.2 \pm 0.57$ \\
P 407 1:3 & $99.5 \pm 0.83$ \\
P $4071: 4$ & $95.7 \pm 0.62$ \\
P $4071: 5$ & $97.6 \pm 0.27$ \\
P 188 1:1 & $94.8 \pm 0.31$ \\
P 188 1:2 & $96.4 \pm 0.84$ \\
P 188 1:3 & $97.3 \pm 0.72$ \\
P 188 1:4 & $99.3 \pm 0.59$ \\
P $1881: 5$ & $97.8 \pm 0.64$ \\
\hline
\end{tabular}

Table 3: Dissolution profile of nisoldipine from poloxamer 407 SD at different drug : carrier ratios.

\begin{tabular}{ccccccc}
\hline \multirow{2}{*}{ Time in min } & \multicolumn{5}{c}{ Percentage nisoldipine dissolved from poloxamer 407 solid dispersions } \\
\cline { 2 - 7 } & Pure nisoldipine & $1: 1$ & $1: 2$ & $1: 3$ & $1: 4$ & $1: 5$ \\
\hline 10 & 1.57 & 19.37 & 28.50 & 39.62 & 44.95 & 59.95 \\
20 & 2.31 & 32.44 & 39.18 & 49.71 & 53.84 & 68.57 \\
30 & 10.85 & 42.61 & 46.29 & 54.59 & 58.19 & 75.28 \\
40 & 14.97 & 49.05 & 52.11 & 65.21 & 69.29 & 81.25 \\
60 & 16.53 & 63.12 & 64.90 & 76.63 & 73.35 & 87.53 \\
90 & 19.41 & 71.20 & 78.18 & 86.88 & 88.95 & 99.13 \\
\hline
\end{tabular}

Table 4: Dissolution profile of nisoldipine from poloxamer 188 SD at different drug : carrier ratios.

\begin{tabular}{ccccccc}
\hline \multirow{2}{*}{ Time in min } & \multicolumn{5}{c}{ Percentage nisoldipine dissolved from poloxamer 188 solid dispersions } \\
\cline { 2 - 7 } & Pure nisoldipine & $1: 1$ & $1: 2$ & $1: 3$ & $1: 4$ & $1: 5$ \\
\hline 10 & 1.57 & 32.61 & 37.25 & 43.48 & 43.96 & 45.78 \\
20 & 2.31 & 37.30 & 43.46 & 52.36 & 53.74 & 57.94 \\
30 & 10.85 & 43.38 & 46.54 & 59.29 & 60.83 & 66.50 \\
40 & 14.97 & 50.19 & 51.29 & 63.71 & 68.51 & 72.69 \\
60 & 16.53 & 56.33 & 54.38 & 74.21 & 78.22 & 79.39 \\
90 & 19.41 & 63.37 & 71.05 & 79.07 & 84.92 & 86.11 \\
\hline
\end{tabular}


Table 5: Dissolution profiles of fast dissolving tablets.

\begin{tabular}{cccccccccccc}
\hline $\begin{array}{c}\text { Time in } \\
\text { min }\end{array}$ & \multicolumn{10}{c}{ Cumulative percentage drug released } \\
\hline & $\begin{array}{c}\text { Control } \\
\text { tablet }\end{array}$ & F1 & F2 & F3 & F4 & F5 & F6 & F7 & F8 & F9 \\
\hline 10 & 6.4 & 51.0 & 57.0 & 63.8 & 53.7 & 59.1 & 64.3 & 49.3 & 54.8 & 60.1 \\
20 & 9.3 & 54.9 & 62.6 & 73.2 & 58.1 & 63.6 & 72.8 & 52.8 & 61.6 & 69.5 \\
30 & 11.7 & 61.0 & 68.1 & 76.9 & 63.6 & 70.2 & 78.1 & 63.7 & 64.8 & 74.3 \\
40 & 16.2 & 69.4 & 76.3 & 84.6 & 72.2 & 77.0 & 89.4 & 73.7 & 71.4 & 79.8 \\
60 & 18.8 & 72.9 & 84.2 & 88.4 & 77.6 & 84.9 & 96.3 & 72.1 & 78.2 & 86.2 \\
90 & 20.4 & 78.9 & 88.4 & 94.3 & 81.9 & 90.8 & 99.6 & 76.8 & 82.5 & 93.7 \\
\hline
\end{tabular}

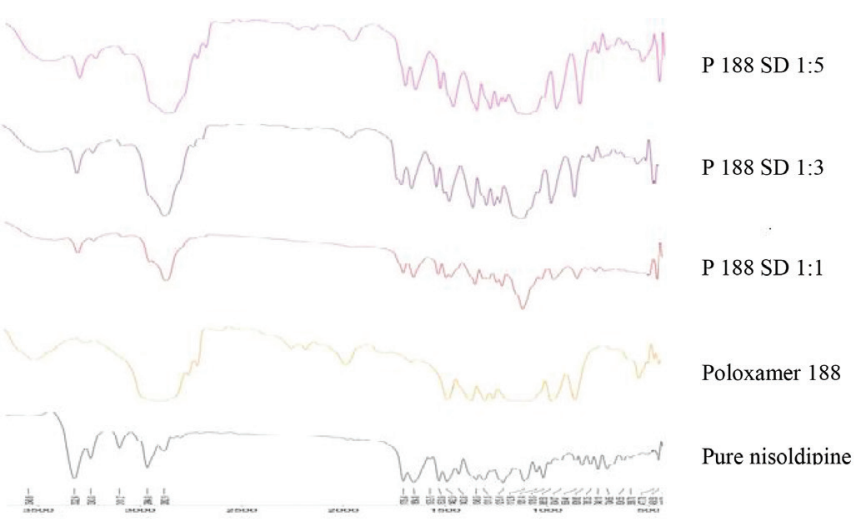

Figure 1: FTIR spectra of nisoldipine, poloxamer 188 and their solid dispersions.

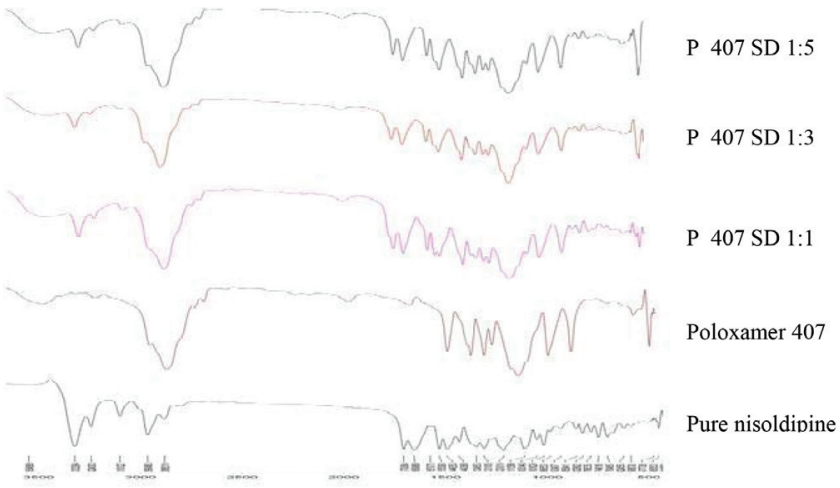

Figure 2: FTIR spectra of nisoldipine, poloxamer 407 and their solid dispersions.

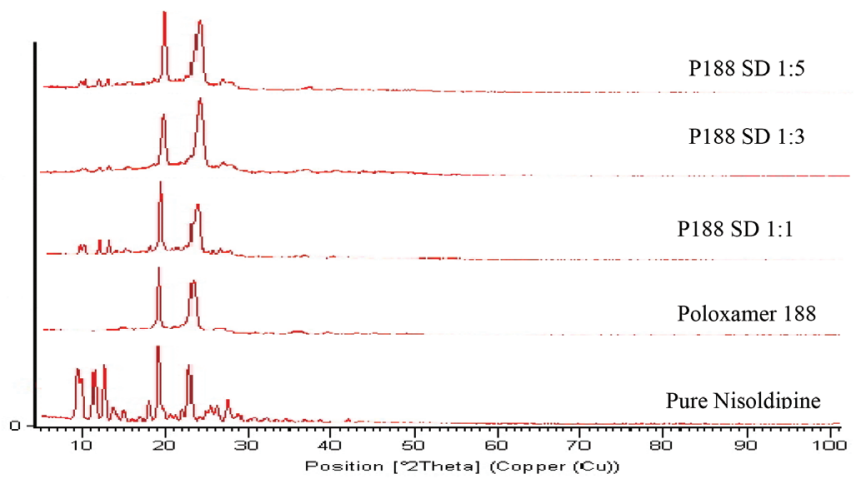

Figure 3: XRD diffractogram of nisoldipine, poloxamer 188 and their solid dispersions.

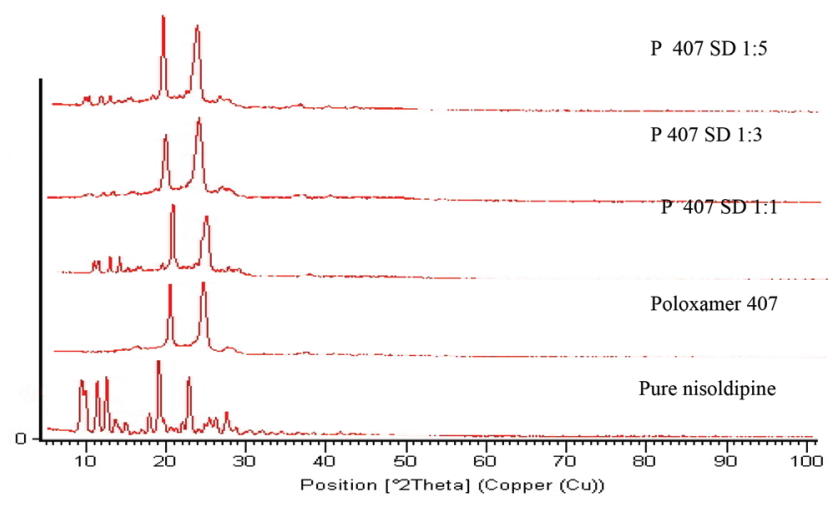

Figure 4: XRD diffractogram of nisoldipine, poloxamer 407 and their solid dispersions.

\section{Differential scanning calorimetry}

The DSC analysis was done for pure nisoldipine and solid dispersions of nisoldipine with P 407 and P 188 which showed higher saturation solubility of pure drug than the polymers used. The DSC thermogram of pure nisoldipine (Figure 5a) showed a sharp endothermic peak at $152.8^{\circ} \mathrm{C}$, which was ascribed to drug melting. The DSC curve of P 407 (Figure 5b) and $\mathrm{P} 188$ (Figure 5c) showed a sharp endothermic peak at $58.9^{\circ} \mathrm{C}$ and $55.5^{\circ} \mathrm{C}$ corresponding to the melting point of $\mathrm{P} 407$ and $\mathrm{P} 188$. It is well established that the enthalpy of transition and entropy of an amorphous solid are much higher than those of its crystalline counterpart. ${ }^{24}$

\section{Scanning electron microscopy}

The SEM analysis of pure drug in Figure 6a showed crystalline in nature and the drug particles were irregular in shape. The solid dispersions of nisoldipine with P 407 and P 188 (Figure 6b-e) showed a homogeneous dispersion indicating that the nisoldipine is dispersed uniformly in carrier matrices of solid dispersions, assuming amorphous solid dispersion state.

\section{Dissolution studies of solid dispersions}

It is well established that, for poorly water soluble drugs, especially class II drugs in biopharmaceutical classification system, improvement of the drug solubility sometimes result in the marked increase in the oral bio availability. To clarify the dissolution behavior of nisoldipine formulation, the dissolution tests on pure nisoldipine and its SDs were carried out upto $90 \mathrm{~min}$ in phosphate buffer $\mathrm{pH}$ 6.8. Figure 7 and 8 shows the dissolution profile of the drug powder in pure state and SDs with different polymers. The dissolution profile of pure drug indicates slow dissolution rate with only $1.57 \%$ of the drug dissolved in first $10 \mathrm{~min}$. The total amount of drug dissolved in 90 min was found to be $19.41 \%$ which revealed its liphophilicity and its crystallinity. Preparation of SD of the drug with $\mathrm{P}$ 407 resulted in a significant increase in the dissolution rate compared to 


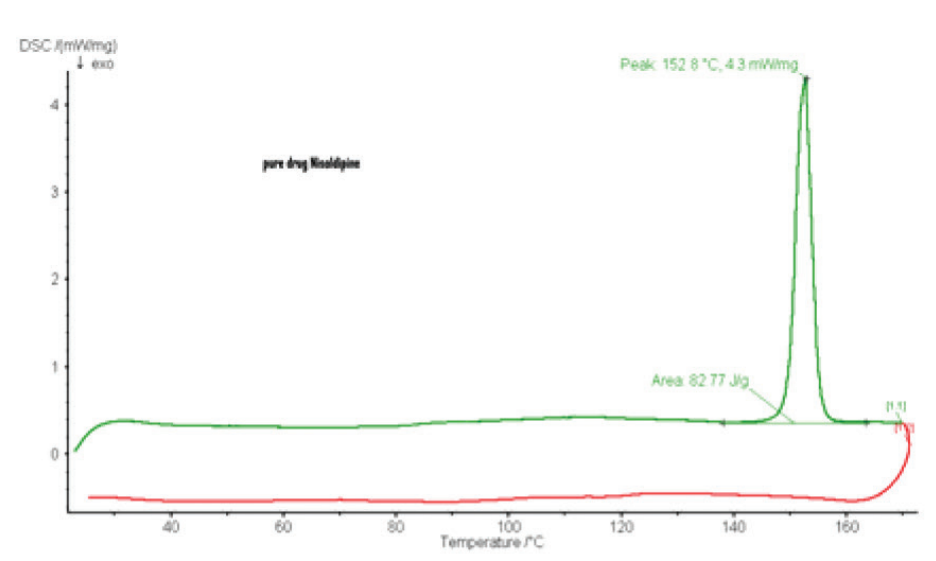

(a)

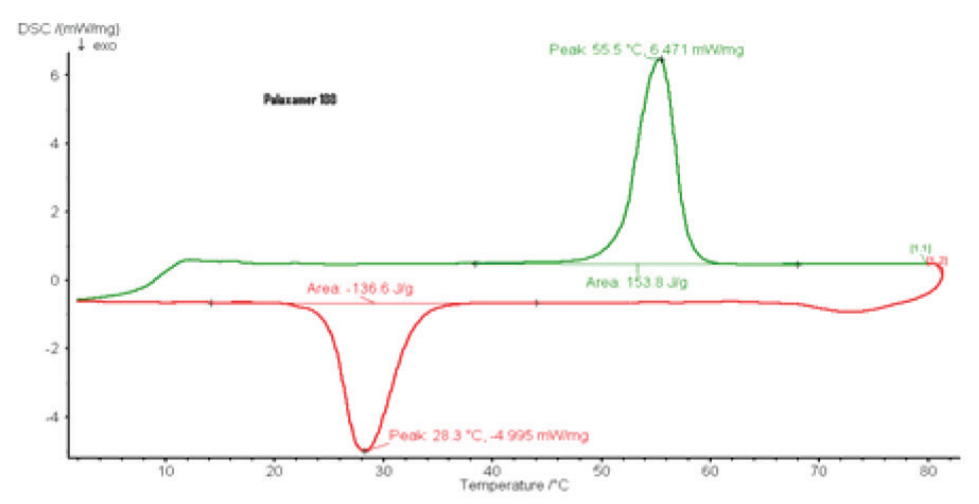

(c)

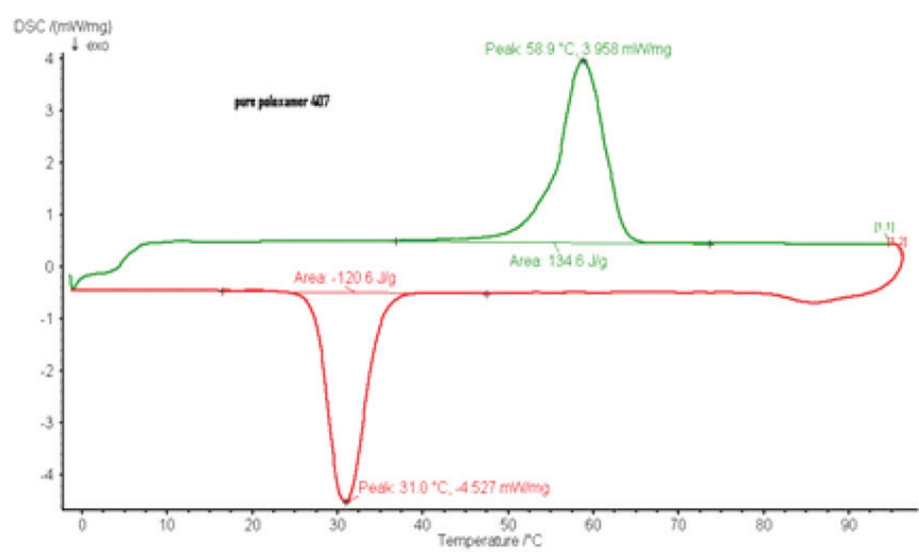

(b)

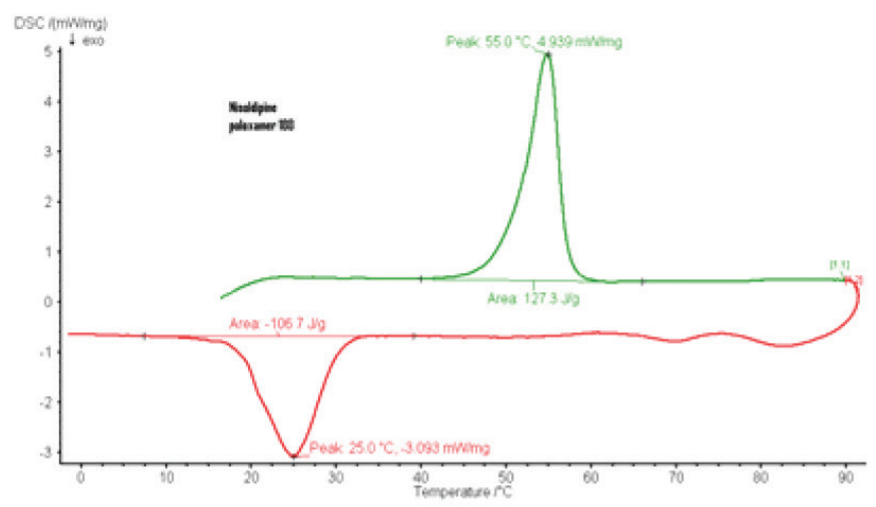

(d)

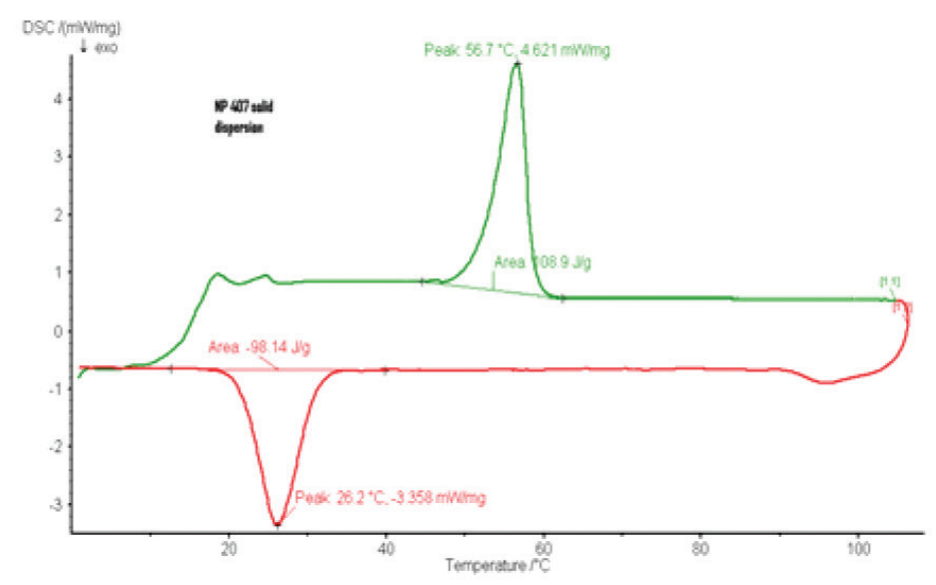

(e)

Figure 5: DSC curve of (a)Pure nisoldipine,(b) P 407, (c) P188, (d)nisoldipinepoloxamer 188 SD 1:5 (e) nisoldipinePoloxamer 407 SD 1:5. 


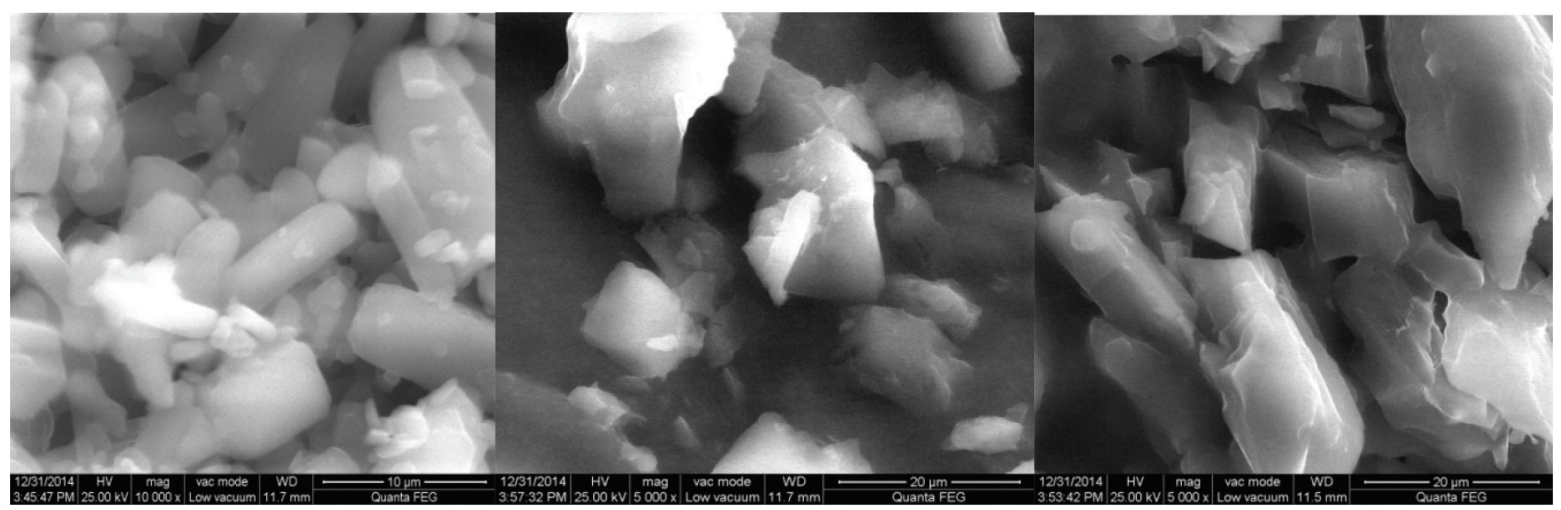

(a)

(b)

(c)

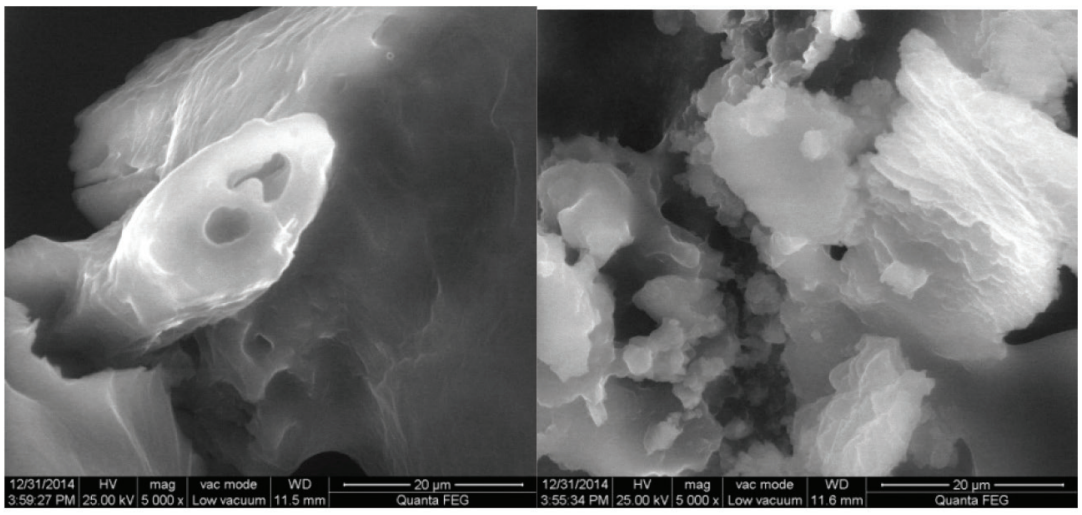

(d)

(e)

Figure 6: SEM microphotograph of (a) Pure drug nisoldipine,(b) nisoldipine P407 SD 1:3 (C) nisoldipine P407 SD 1:5 (d) nisoldipine P188 SD 1:3 (e) nisoldipine P188 SD 1:5.

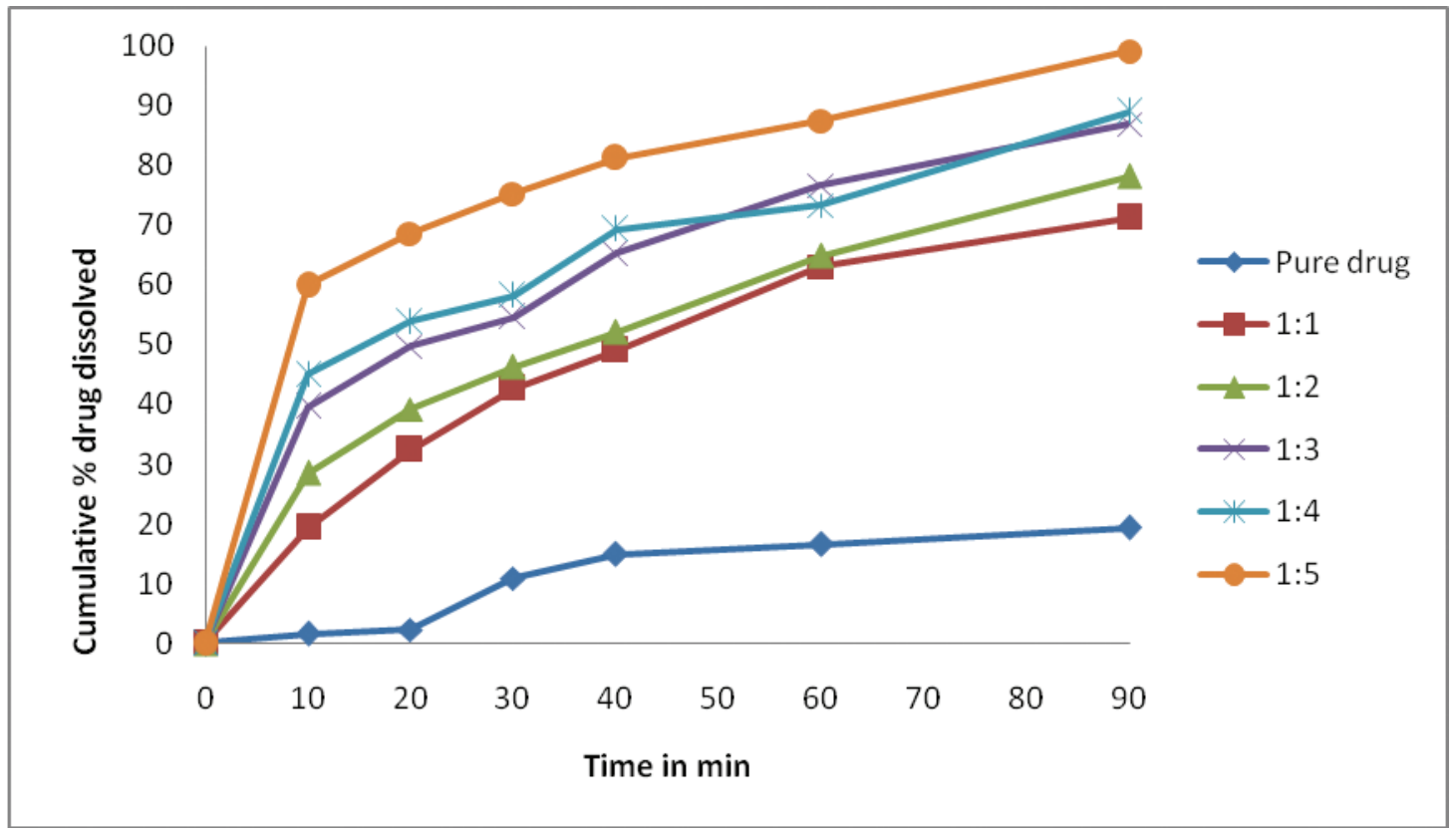

Figure 7: Dissolution profile of nisoldipine from poloxamer 407 SD at different drug : carrier ratios. 


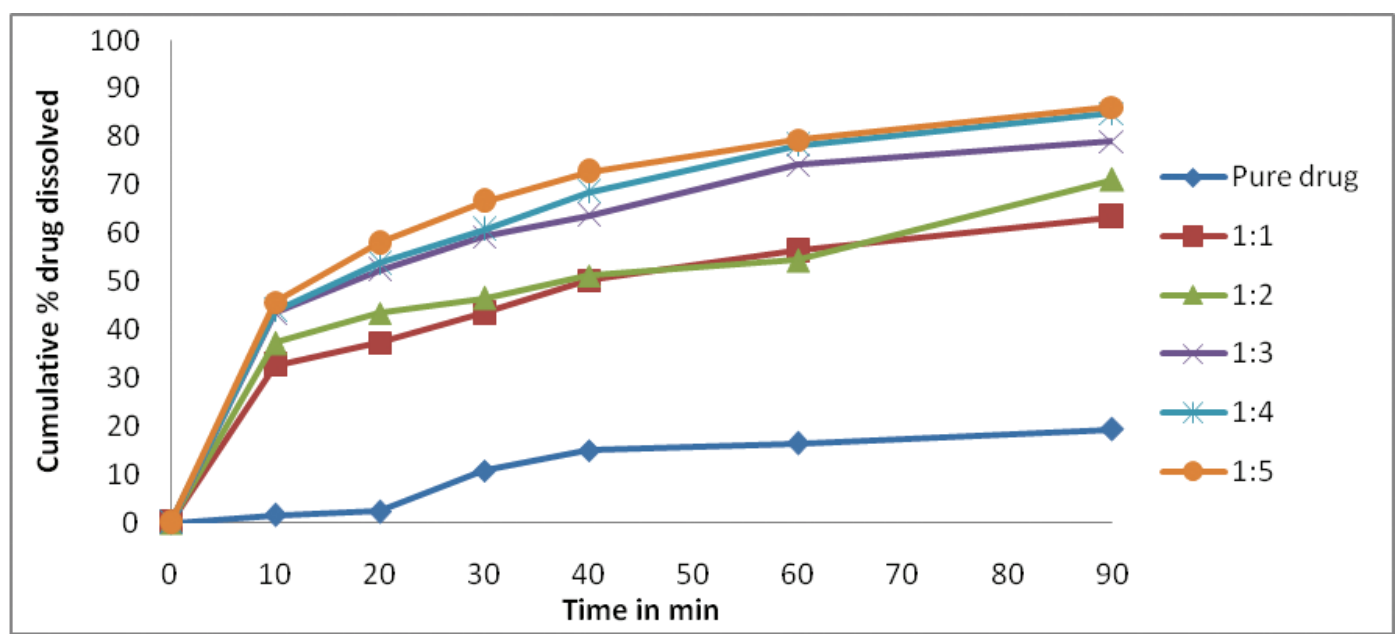

Figure 8: Dissolution profile of nisoldipine from poloxamer $188 \mathrm{SD}$ at different drug : carrier ratios.

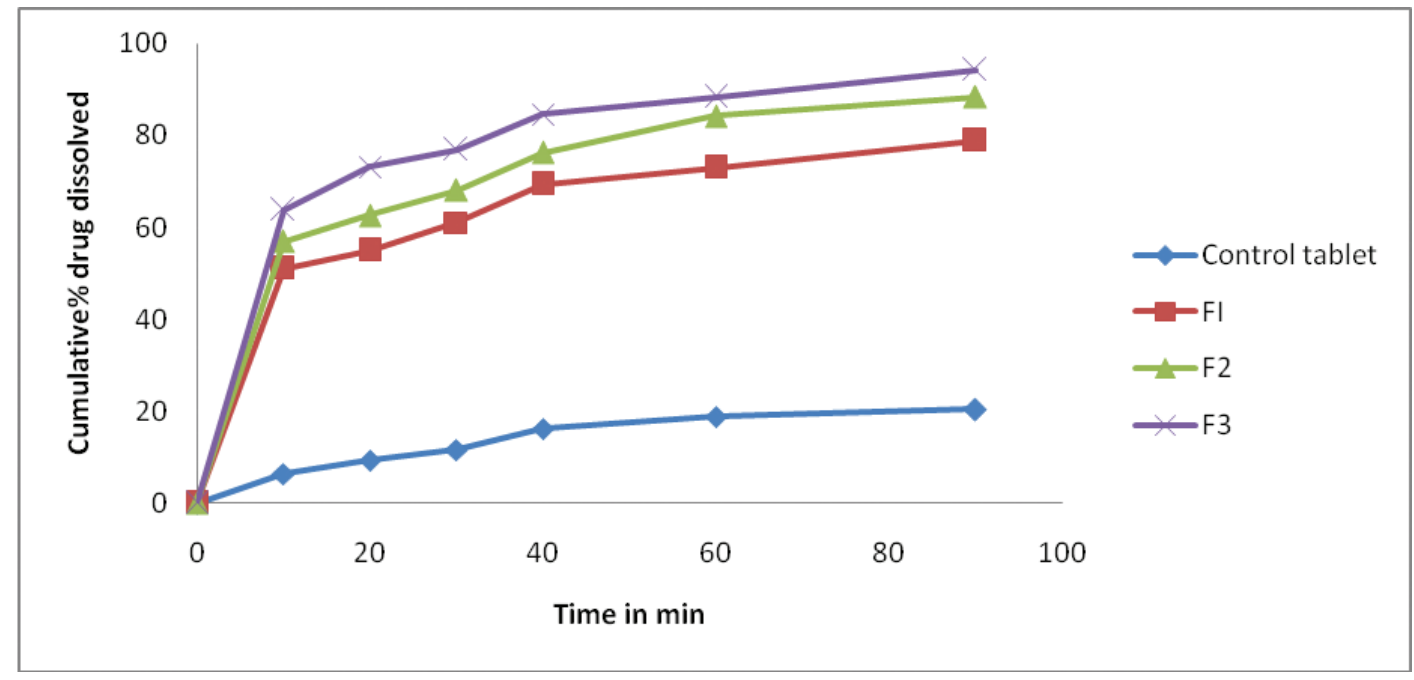

Figure 9: Dissolution profiles of control tablet and tablets containing SD with crospovidone as superdisintegrant.

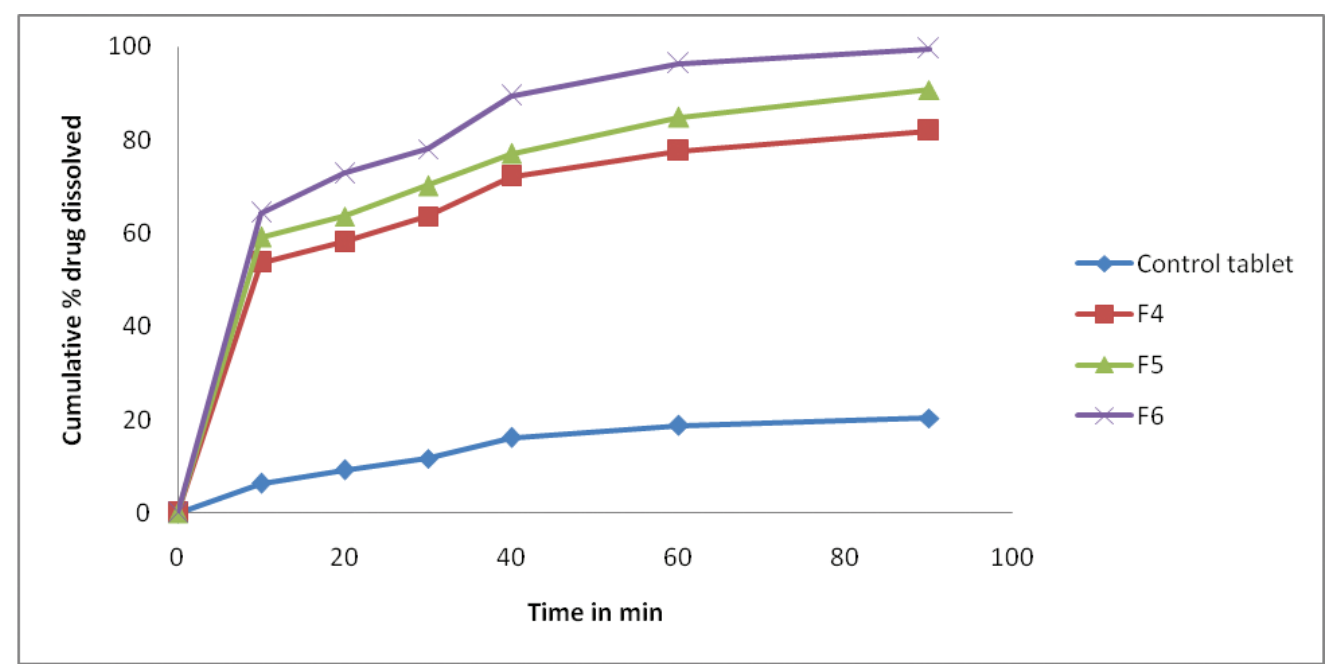

Figure 10: Dissolution profiles of control tablet and tablets containing SD with croscarmellose sodium as superdisintegrant. 


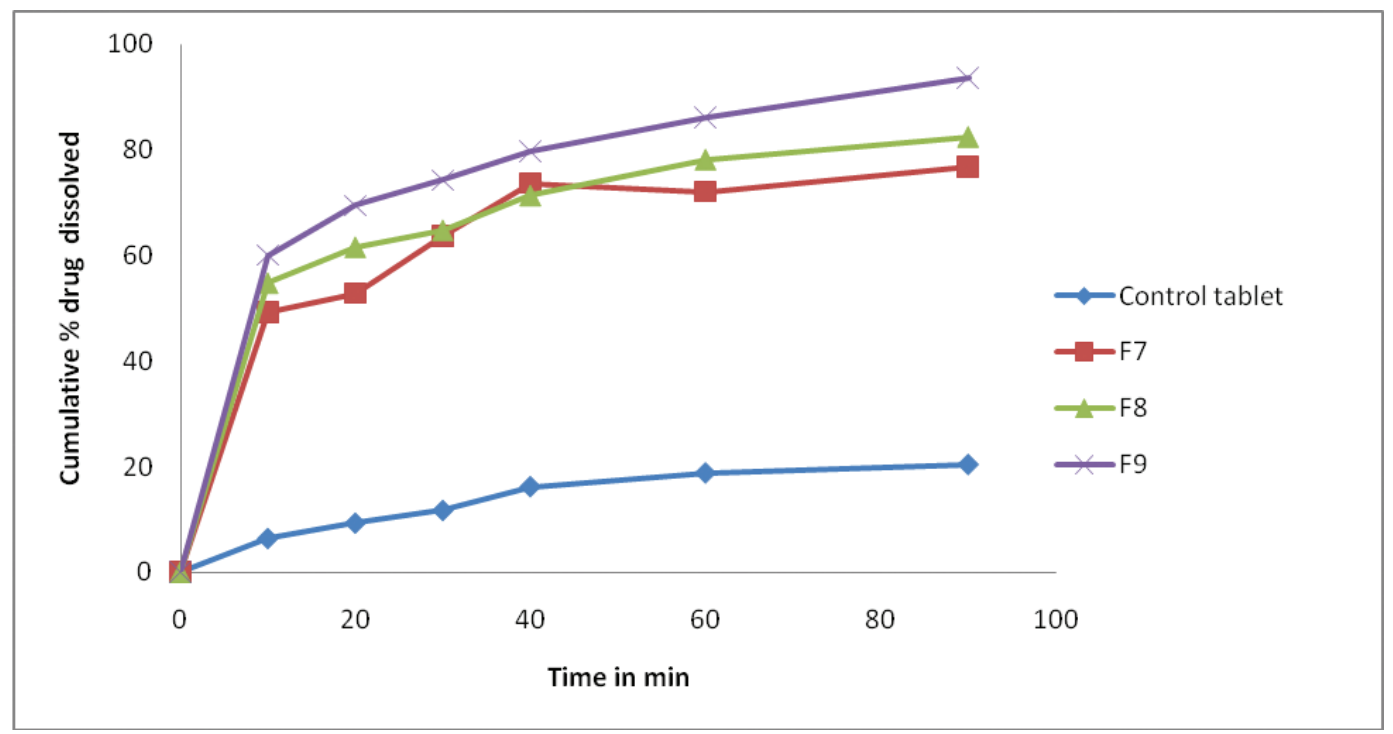

Figure 11: Dissolution profiles of control tablet and tablets containing SD with sodium starch glycolate as superdisintegrant.

the pure drug. The enhancement of dissolution depended on the concentration of polymer in the SD. So the amount of drug released in the first 10 min was increased gradually with increase in polymer concentration to reach $99.13 \%$ at $1: 5$ (drug to polymer weight ratio) which is higher than that of pure drug or SDs containing lower proportions of P 407.

For P 188, preparation of SD with the drug resulted in gradual increase in the dissolution rate at low polymer concentration so that the amount of drug dissolved in the first 10 min was $32.61 \%$ in case of $1: 1$ (drug to polymer, weight ratios). This amount increased significantly in case of $1: 2,1: 3,1: 4$ and reached $86.11 \%$ of the labeled amount in 1:5 ratio. This result shows the need for higher concentrations of the polymer to convert it into amorphous form and to achieve better dissolution parameters. ${ }^{25}$

\section{Characterization of tablets}

The prepared tablets were found to be of uniform in weight and the weight variation was within the limit of $7.5 \%$. The friability of all formulations was found to be less than $1 \%$. The result shows resistant to loss of weight indicates the tablet ability to withstand abrasion in handling, packaging and shipment. The hardness of tablet ranged from $3.5-4 \mathrm{Kg} / \mathrm{cm}^{2}$. The percent drug content was found to be $100 \pm 5 \%$.

\section{In vitro study of tablets}

It was observed that the disintegration time of the tablets decreased with increase in proportion of superdisintegrants used in the formulation. It indicates that increase in the level of superdisintegrants (crospovidone, croscarmellose sodium and sodium starch glycolate) had a positive effect on disintegration of fast dissolving tablets. The disintegration time of tablets follows the pattern with various superdisintegrants:

Croscarmellose sodium $<$ crospovidone $<$ sodium starch glycolate.

The dissolution behavior of various formulations and the control tablets were shown in Figure 9-11. The drug release from various formulations followed the order: F6 $>$ F3 $>$ F9 $>$ F5 $>$ F2 $>$ F8 $>$ F4 $>$ F1 $>$ F9. The pattern provides an idea about the effect of super disintegrants in drug release profile of fast dissolving tablets.

\section{DISCUSSION}

All the solid dispersions were uniform in drug content and the IR spectra of nisoldipine and its solid dispersions are identical. The principle IR absorption peaks of nisoldipine solid dispersions were observed and found to be identical with the spectra of nisoldipine pure drug. Thus from the spectra it was understood that there was no interaction between nisoldipine and the carriers used in the preparation of solid dispersions. The XRD studies revealed that the crystallinity of nisoldipine is reduced in solid dispersions. In DSC studies, the peak temperature in solid dispersion was shifted to lower temperature (Figure 5d, Figure 5e) with respect to the drug, and there was a decrease in $\Delta \mathrm{H}$ value of nisoldipine solid dispersion $\left(-108.9 \mathrm{Jg}^{-1}\right.$ and $\left.127.3 \mathrm{Jg}^{-1}\right)$ compared to the pure nisoldipine $\left(-82.77 \mathrm{Jg}^{-1}\right)$. These phenomena could be attributed to the amorphous form of the nisoldipine in solid dispersion. From the dissolution studies of solid dispersions it is concluded that the rate of dissolution increases with an increase in carrier concentration. Among the carriers used P 407 SDs gave fastest dissolution. The in vitro drug release profile of fast dissolving tablets was found to be increased with increase in superdisintegrant level. The highest drug release was observed in croscarmellose sodium, followed by crospovidone and sodium starch glycolate. The fast dissolving tablets containing croscarmellose sodium (6\%) showed the highest drug release ( $99.6 \%)$. The control tablets were prepared with croscarmellose sodium (6\%) with other ingredients using pure nisoldipine and the dissolution profile is compared with the formulation containing solid dispersion of drug (Figures 9-11).

\section{CONCLUSION}

In the present study, the solid dispersions of nisoldipine were prepared with poloxamer 188 and poloxamer 407 with aim of enhanced dissolution rate. The fastest drug release was obtained from nisoldipine poloxamer SD in the ratio of 1:5 prepared by solvent evaporation method. The formulation of fast dissolving tablets by using solid dispersion of nisoldipine is unique technique by which the dissolution rate of drug can be enhanced which is most challenging aspect of drug delivery. The technique adopted was found to be economical and industrially feasible. Thus, it can be concluded that combination of solid dispersion technology and using superdisintegrants in the formulation is a promising approach to prepare efficient fast dissolving tablet of poorly water soluble drug nisoldipine. 


\section{ACKNOWLEDGEMENT}

The authors thankful to SRM College of Pharmacy, Kattankulathur, Tamilnadu for helping to carry out this research work

\section{CONFLICT OF INTEREST}

Authors declare that there is no conflict of interest, so nothing to disclose.

\section{ABOUT AUTHORS}

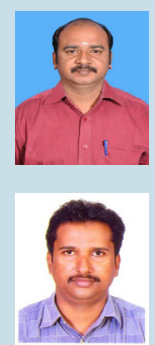

V. Manimaran: Is an Assistant professor in SRM College of Pharmacy, SRM university. He graduated his Bachelor of Pharmacy and Master of Pharmacy from Tamilnadu Dr.M.G.R Medical university. His Doctoral research focused on the development of fast dissolving tablets of anti-hypertensive drugs using solid dispersion technology.

N. Damodharan: Obtained his Ph.D degree in 2008 from the Department of Pharmaceutical Technology, Jadavpur University, Kolkata. Currently he is positioned as Professor and Head, Department of Pharmaceutics, SRM College of pharmacy, SRM University. Dr. N. Damodharan is working on various aspects of drug delivery systems including Transdermal drug delivery, Nanoparticles and Solid dispersion.

\section{REFERENCES}

1. Milo Gibaldi. Biopharmaceutics and clinical pharmacokinetics. $4^{\text {th }}$ ed. Philadelphia: Lea \& Febiger; 1991.p.24-37.

2. Nadia S, Riaz U, Naz H, Kumar B. Enhancement of oral bioavailability and solid dispersion: A review. J Appl Pharm Sci. 2011;1(7):13-20.

3. Christian L, Jennifer D. Improving Drug solubility for oral delivery using solid dispersions. Eur J Pharm Biopharm. 2000;50(1):47-60.

4. Srinarong P, Faber JH, Visser MR, Hinrichs WLJ, Frijlink HW. Strongly enhanced dissolution rate of fenofibrate solid dispersion tablets by incorporation of superdisintegrants. Eur J Pharm Biopharm. 2009;73(1):154-61.

5. Eun-jung K, Myung Kwan C, Jae-Sang J, ljn-Hwa L, Kyo-Re L, Hoo-kyun C. Preparation of solid dispersion of felodipine using a solvent wetting method. Eur J Pharma Biopharm. 2006;64(2):200-5

6. Dhirendra K, Lewis S, Ududpa N, Atin K. Solid dispersions a review. Pak J Pharm Sci. 2009;22(2):234-46.

7. Sethiya S, Squillante E. Solid dispersion of carbamazepine in PVPK30 by conventional solvent evaporation and super critical methods. Int J Pharm. 2003;272(1):1-10.

8. Nirav P, Jayavadan P. Dissolution enghancement of anti depressasnt escitalopram oxalate by solid dispersion technique. J Curr Pharm Res. 2012;9(1):26-32

9. Ruchi T, GauravT, Birendra S, Awani R. Solid dispersions: An overview to modify to modify bioavailability of poorly water soluble drugs. Int J Pharm Tech Res. 2009;1(4):1338-49.

10. Satomi O, Hideyuki S, Kumiko O, Yohei K, Takahiro M, Kayo Y, et al. Improved dissolution and pharmacokinetic behavior of cyclosporine A using high-energy amorphous solid dispersion approach. Int J Pharm. 2010;399(1):94-101.

11. Sambamoorthy U, Madanmohan K, RohitreddyT, Someshear K, Kumaraswamy D. Formulation of sustain release solid dispersions of verapamil hydrochloride using ethyl cellulose and eudragit-Rspo. Int J Pharm Pharm Sci. 2011;3(1):116-22.

12. Heike B, Bernd F, Roland B. Characterization and stability of solid dispersions based on PEG/Polymer blends. Int J Pharm. 2010;390(2):165-73.

13. Xingwang Z, Ningyun S, Baojian W, Yi L, Tianzheng G, Wei W. Physical characterization of lansoprazole/PVP solid dispersion prepared by fluid-bed coating technique. Powder technol. 2008;182(3):480-5.
14. Veerendra R, Pankaj R, Surender G, Harish D, Gitika A, Manju N. Formulation and characterization of solid dispersion of glimepride through factorial design. Iran J Pharm Sci. 2011;7(1):7-16.

15. Seoung W, Min-soo K, Jeong-soo K, Hee Jun P, Sibeum $L$, Jong-soo W et al. Preparation and characterization of simvastatin/hydropropyl- $\beta$-cyclodextrin inclusion complex using supercritical antisolvent (SAS) process. Eur J Pharm Biopharm. 2007;66(3):413-21.

16. Veiga $F$, Teixeirra $D$, Kedzeirewicz F, Sousa $A$, Maincent $P$. Inclusion complexation of tolbutamide with $\beta$-cyclodextrin and hydroxylpropyl- $\beta$-cyclodextrin. Int J Pharm. 1996;129(1):63-71.

17. Keshav R, Deshmuk, Sunil KJ. Development of aceclofenac mouth dissolving tablets using solid dispersion technique: In-vitro evaluation. Ind J Pharm Edu Res. 2012;46(2):97-104

18. Jachowicz R, Nurnberg E, Pieszczek B, Kluczykowska B, Maciejewska. Solid dispersion of ketoprofen in pellets. Int J Pharm. 2000;206(1):13-21.

19. Kranthikumar M, Lakshmi PK, Giriprasad VS. Development and evaluation of solid dispersion formulated ibuprofen tablets using cyclodextrins as carrier. Int J Pharm Res Dev. 2012;3(11):93-101.

20. Ravi K, Patil MB, Sachin RP, Mahesh SP. Formulation and evaluation of effervescent floating tablet of famotidine. Int J Pharmtech Res. 2009:1(3):754-9.

21. Van drooge DJ, Hinrichs WLJ, Frijlink HW. Anomalous dissolution behavior of tablets prepared from sugar glass-based solid dispersions. J Controlled Release. 2004;97(3):441-52.

22. Patil SA, Kuchekar BS, Chabukswar AR, Jagdale SC. Formulation and evaluation of extended release solid dispersion of metformin hydrochloride. J Young Pharm. 2010;2(2):121-9

23. Gamal M, Maghraby El, Ramy E. Fast disintegrating tablets of nisoldipine for intra oral administration. Pharm Dev Technol. 2014;19(6):641-50.

24. Friesen DT, Shanker R, Crew M, Smithey DT, Curatolo WJ, Nightingale JA Hydroxypropyl methylcellulose acetate succinate-based spray-dried dispersions: an overview. Mol Pharm. 2008:5(6);1003-19

25. Yusuke S, Makiko F, Yuka S, Ryusuke Y, Shinji F, Sayaka N. The preparation of a solid dispersion powder of indomethacin with crospovidone using a twin-screw extruder or kneader. Int J Pharm. 2009:365(1):53-60. 